\title{
Micropulse lidar observation at Gauhati University for understanding atmospheric dynamics on aerosol -cloud interaction \& precipitation
}

\author{
M. Devi ${ }^{1}$, A. K. Barbara ${ }^{1}$ and A. Depueva ${ }^{2}$ \\ ${ }^{1}$ Department of Physics, Gauhati University, \\ Guwahati 781014, Assam, India \\ 2 \\ IZMIRAN, Troisk, Moscow , Russia \\ *Email:md555@sify.com
}

\begin{abstract}
The paper presents process of development of cloud within temporal scale of minutes and consequent formation of precipitations through lidar observation of Gauhati University (GU, $26^{\circ} \mathrm{N}$ and $92^{\circ} \mathrm{E}$ ) .

For this purpose modifications in optical properties of aerosol and cloud are examined for precipitating and non precipitating situations by monitoring backscatter (BS) counts obtained from aerosol and cloud. The case studies demonstrates that cloud base movement registered a downward motion prior to a rain event and simultaneously aerosol counts show a sudden surge before development of rain. The paper focuses association of aerosol extinction coefficient $(\sigma)$ with rain bearing cloud and hence in lidar ratio ( $S=\sigma / \beta$, where $\beta$ is the backscatter coefficient). Further light scattering features from rain droplets are extracted from BS counts and the observed features are expressed in terms of rain rate. For calibration of lidar derived rain rate, surface rain is simultaneously measured by a Distrometer as well as by rain gauge at the lidar site Finally a few cases on derived rain magnitude and those recorded by rain gauge are presented .
\end{abstract}

Key words: lidar; radar; aerosol; cloud; rain; disdrometer.

\section{Introduction}

The Portable Atmospheric Lidar (PAL) or aerosol lidar has the ability to provide continuous data of aerosols, dust particles and clouds. It can offer both geometric and microphysical properties especially of clouds [Campbell et al., 1998 ; Stokes and Schwartz, 1994] of different types. Further, since aerosol particles serve as cloud condensation nuclei, the output of such lidar can be used for understanding aerosol-cloud radiative association [Bian et al., 2009; Graß1, 1975]. Thus lidar backscatter signals are 
effective in framing of atmospheric models for estimation of cloud radiative forcing at different cloud types [Hobbs, 1993]. Reports on detection of cloud base and hydrometeor information from lidar echograms are also available [Clothinux et al., 1998].

In this paper indirect effect of aerosol on cloud leading to precipitation, is presented from lidar observation at Gauhati University (GU), situated in a semi urban environment of North East part of Indian subcontinent. Starting with cloud types and their base height modification features, precipitation conditions seen in lidar echograms are first examined along with corresponding variations in backscatter (BS) aerosol counts. Additional inputs from rain gauge are taken when necessary. Approaches adopted for calculating rain rate from lidar counts and the calibration processes are discussed along with the reliability aspect of rain rate so measured. A method for identifying rain bearing clouds from the extinction coefficients of aerosols is also suggested in the paper.

\section{Observation and analysis}

\subsection{GU Lidar, Cloud, Aerosol and Precipitation}

The data obtained for this analysis are collected from a lidar [designed after Spinhirne, 1993; Spinhirne et al., 2000] of Gauhati University, which transmits $532 \mathrm{~nm}$ pulses of width $10 \mathrm{~ns}$ at Peak Repetition Frequency (PRF) of 1 KHz [Devi and Barbara, 2004 ; Devi et al., 2009 ; Devi et al., 2011 ]. The BS signals from the atmosphere collected by a telescope of diameter $20 \mathrm{~cm}$ are amplified with a Photo Multiplier Tube (P.M.T). The output is then processed in LabView environment by a software developed [Baishya et al., 2003; Devi et al., 2009] for obtaining aerosol and cloud features. The system receives back scatter counts from aerosols and clouds up to a height of 5 and $15 \mathrm{~km}$ respectively at a resolution of $15 \mathrm{~m}$. The bin time is $100 \mathrm{~ns}$ and average integration time of one profile is generally kept at $20 \mathrm{~s}$. Normalization of bs counts with laser power and background count is done along with correction for distance square attenuation and system calibration [Baishya et al., 2003 ; Devi and Barbara , 2003 ; Devi et al., 2009 ; Devi et al., 2012 ]. The unit is a coaxial one and with this high PRF it can resolve fraction of one photon, after normalization.

To achieve the above aims, we start our analysis by examining "rain-time" and "no rain-time" lidar echograms; a few examples are presented below: 


\subsubsection{Cloud and aerosol features seen by GU LIDAR before and after surface rain events}

A representative rain-time lidar echogram is presented in Figure 1. We call it rain -time echogram because surface rain was registered from 18:10 hrs. and 18:20 hrs., by a rain gauge as shown in Figure 2a. We now examine the lidar echogram of Figure 1, in relation to aerosol, rain and cloud. The two arrows mark in the figure correspond to the time interval when rain was recorded by the rain gauge (RG) and during this period strong BS signals from very near to the surface were received by the lidar. Thus these scatter zones are associated with surface rain. It is also seen that (i) a downward motion of low lying cloud-base starts from an altitude of $800 \mathrm{~m}$ to around 500m and (ii) an apparent enhancement of aerosol counts (green background) before rain signature was captured. Aerosol counts gradually subside after the rain ends. Formation of another low lying cloud structure is seen at around 18:45 hrs. with gradual downward motion of cloud height along with increase in background aerosol, but this motion is suddenly reversed and cloud base has moved up. No precipitation signature is seen in the echogram and no surface rain was reordered by the rain gauge during this period.

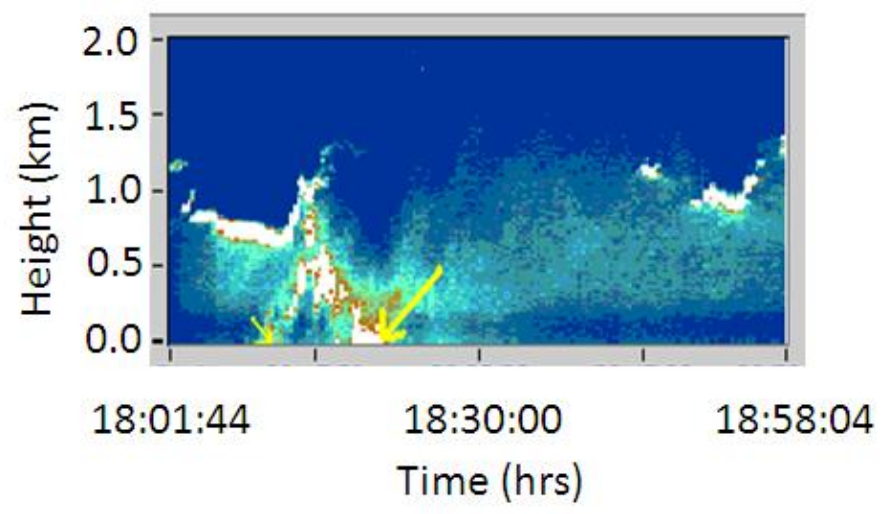

Figure1. Shows development of surface rain events of 7.11.2001, when low altitude cloud-base displays a rapid downward motion. Enhancement in background aerosol count prior to the events is to be noted. Rain events are marked by arrows.

\subsubsection{Relation between lidar backscatter signal and rain}

The lidar counts seen as white marks in the echogram during rain, are to compare with rain (in mm) registered by rain gauge for calibration of counts with rain fall. For this purpose we take near surface lidar counts of the events shown in Figure 1. However for such analysis finer details of each profile of 20s are recorded and then data for three profile period that is 1minute (not shown in this figure) are taken. These counts are then compared with rain data from Fast response Rain Gauge (FGR). In Figure 2(b) we present rain time lidar counts from 18:05 hrs. to 18:25 hrs. , along with the rain gauge data of Figure 2(a). 
Rain gauge had registered rain of intensity 0.5 to $0.2 \mathrm{~mm}$ during 18:15 hrs. to 18:20 hrs., when lidar also shows corresponding changes of counts in that interval. This observation establishes an association between counts and rain rate. One can however note the finer details of the rainfall feature in lidar counts [Figure 2(b)] compared to rain gauge data because lidar shows three events of short durations while rain gauge gives integrated one output of these events.

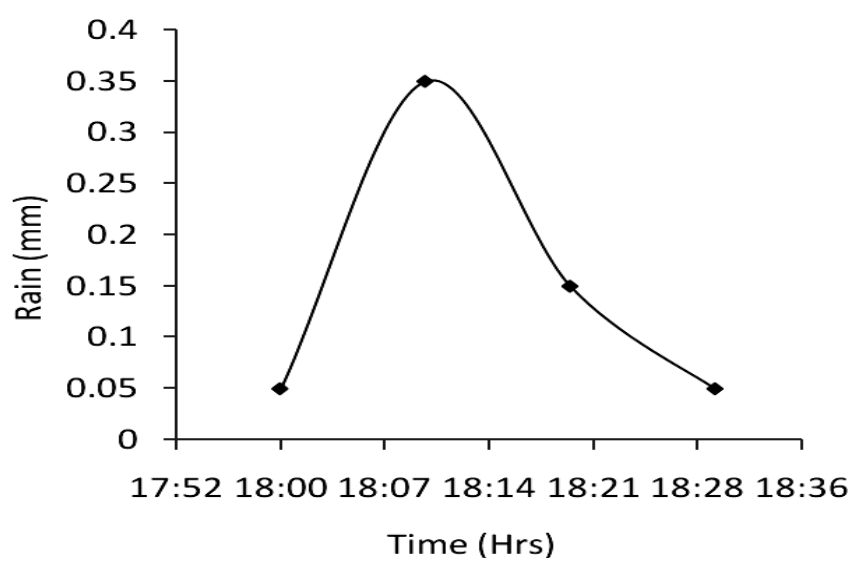

(a)

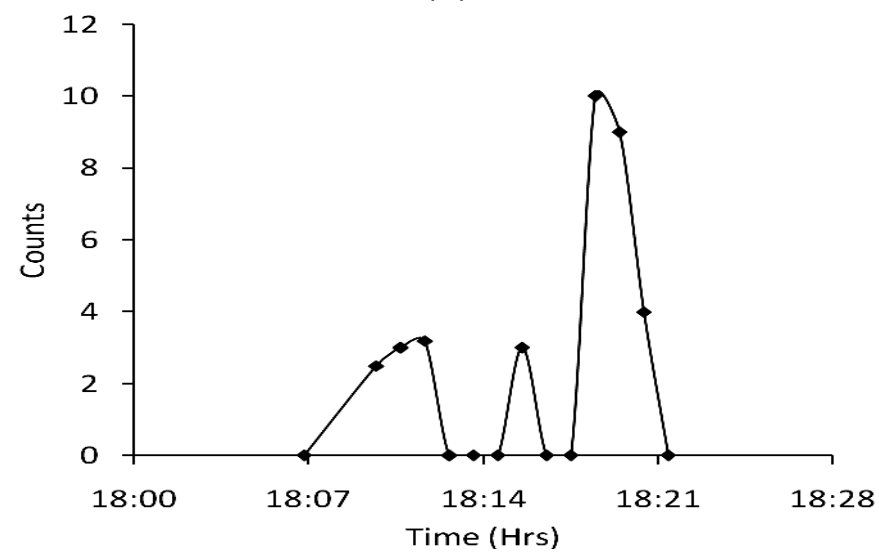

(b)

Figure 2. Shows (a) rain gauge output on 7.11.2001 and (b) lidar counts for the same time interval on 7.11.2001.The observation indicates that lidar echogram can offer information on development of a surface rain event. Note the finer temporal resolution of precipitation in lidar records.

However, it is essential to examine a few more echograms to assess the strength of association between cloud development, precipitation and aerosols and a few lidar echograms relevant to this work are thus presented. Figure 3(a) presents a post monsoon evening cloud structure with aerosols in the background. Here, we note that there is an apparent enhancement of aerosols around the base of layered cloud structure (above $2 \mathrm{~km}$ ) but downward movement of cloud-base, a suggestive pre requisite condition for development of precipitation, is not seen . Therefore, rain is not expected during this period and this status was verified by the rain gauge output. 
Another lidar echogram carrying rain signature (marked by arrow heads) for two events is shown in Figure 3(b). Prior to each precipitation, lidar echogram indicates downward motion of low lying cloud base. However on this day echogram is not sharp as in night time conditions because of strong background noise at the day time, but in spite of the noisy ambiance, cloud base movement before each rain event could be detected.

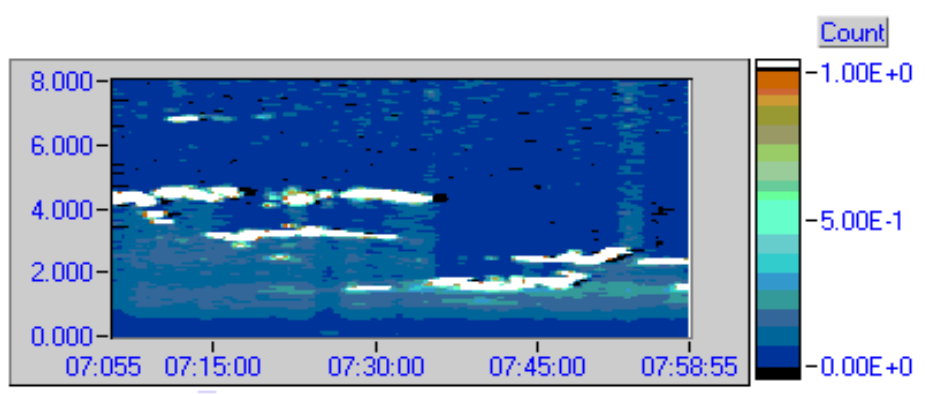

(a)

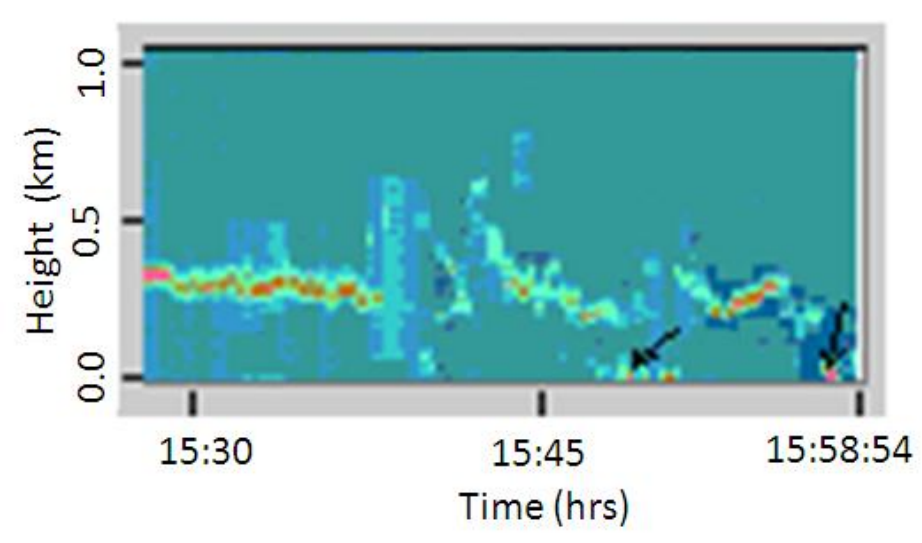

(b)

Figure 3. (a) Post monsoon layered cloud structure. Here we note that there is an apparent enhancement of aerosol around the base of layered cloud structure (above $2 \mathrm{~km}$ ) but downward movement of cloud-base, is absent. No surface rain was recorded. (b) Another post monsoon rain signature. Low base cloud develops downward motions and surface rains were noted as marked by arrow heads in the figure. Noise in the background is due to day-time bright environment.

\subsubsection{Cloud and aerosol features in initiating precipitation condition at higher altitude}

It will also be interesting to examine whether lidar can offer precipitation condition at higher altitudes, in addition to our findings at the surface. With such an aim a case is presented in Figure 4a, where rain- time backscatter was visible at altitude of $5 \mathrm{~km}$ during 18:20 hrs. to 18:35 hrs. We associate this event with rain development process because during this period the spread of scattering zone and downward motion of the cloud base is similar to those exhibited by low lying clouds [Figure 1 and Figure 3(b)]. However in 
this event surface rain did not materialize (no rain was recorded by rain gauge) and the down draught of the cloud-base is inhibited and reversed soon after its formation. Significantly, along with this upward movement of cloud-base, backscatter counts from aerosol have gone down [Figure 4(a)]. Cloud -base height variation in time sequence of this event offered by lidar shows that cloud base movement has a downward trend from 18:15 hrs for about 20 minutes followed by an upward motion and remained at heights $\geq 4 \mathrm{~km}$ up to 19:00 hrs and thus the purported pre-condition for develop of rain has not been satisfied and further precipitation process is inhibited. This observation also suggests that downward movement of cloud-base with high aerosol density at the background play significant role in initiating rain formation process and a lidar can identify such event even at an altitude of 4 to $5 \mathrm{~km}$.

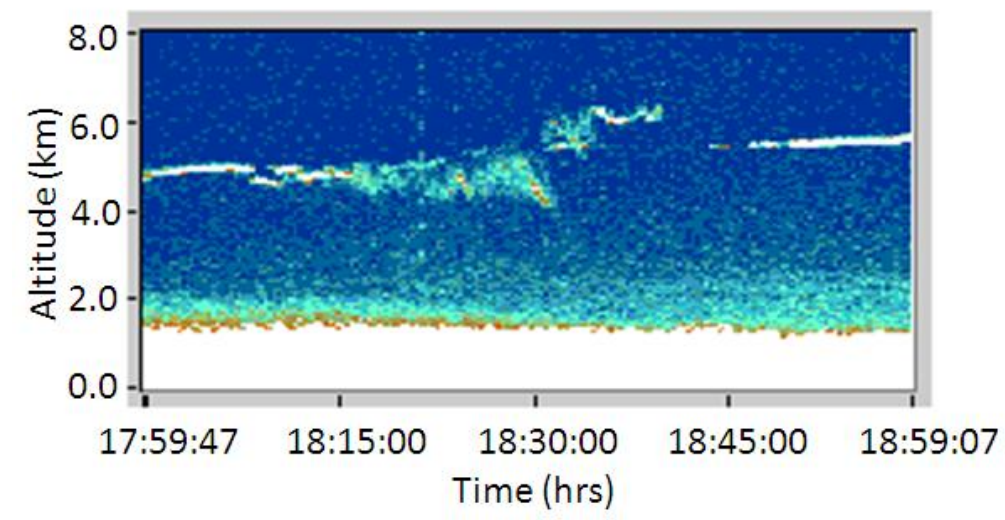

(a)

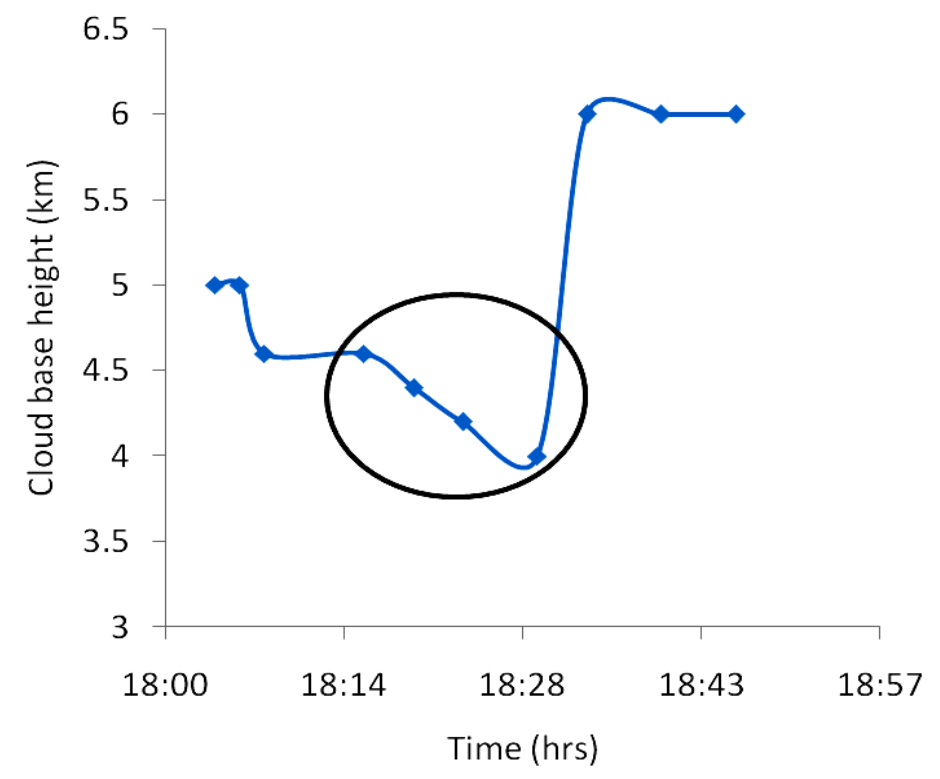

(b)

Figure 4. (a) A representative lidar echogram (of 5.3.2001) when relatively high altitude cloud at $5 \mathrm{~km}$, develops a rapid short lived downward motion during 18:15-18:35 hours, suggesting precipitation at heights of around 4-5 km. Cloud base height observation from lidar for the evening of 5.3.2001 is shown in (b). Drop in base altitude during the formation of precipitation process (shown by circle) is noted. 
Thus in macroscopic view, the high density background aerosol and cloud-base height modifications are normally observed in the process of development of precipitation either at the surface or at higher altitudes.

\subsection{Rain Rate measurements from Lidar and Disdrometer observation}

For converting lidar counts to rain rate, we will use disdrometer data on Rain Drop Size Distribution (RSD). The disdrometer is selected here for calibration of backscatter counts because this system can provide a matching rain rate resolution to the integrated lidar bin time of 1 minute. Before discussing the process of calibration of lidar counts to rain intensity, it is necessary to identify their imprints on lidar echogram.

Rain time counts of lidar returns from very near to the surface are monitored and compared with those when there is no rain. The difference is classed as rain -counts. These counts are measured for each bin time of 20s and then integrated for three bins. This period gives rain -count for each minute. It is then compared with rain drop measurements from disdrometer and finally to rain rate. The process of obtaining rain counts is presented in Figure 5(a). Here lidar counts at 1 minute interval windows of a very low rain event are shown. We note that after the third window onwards, counts begin to increase rapidly to a maximum of 4.2 counts at 1506 hours. A spell of rain (during 15:00-15:10hrs) of 4-5mm/h registered by the rain gauge confirms that lidar counts of 15:00-15:10 hrs are associated with rain. Simultaneous observations of Radar [Figure 5(b)] from Regional Meteorological Centre (RMC) situated at a distance of $1 \mathrm{~km}$ in line of sight path from the lidar site also indicate the downward motion of the base height variations of both Strato-Cumulus (SC) and mid altitude Alto -Cumulus (AC) clouds before the rain event registered at 14:45-15:00 hrs.

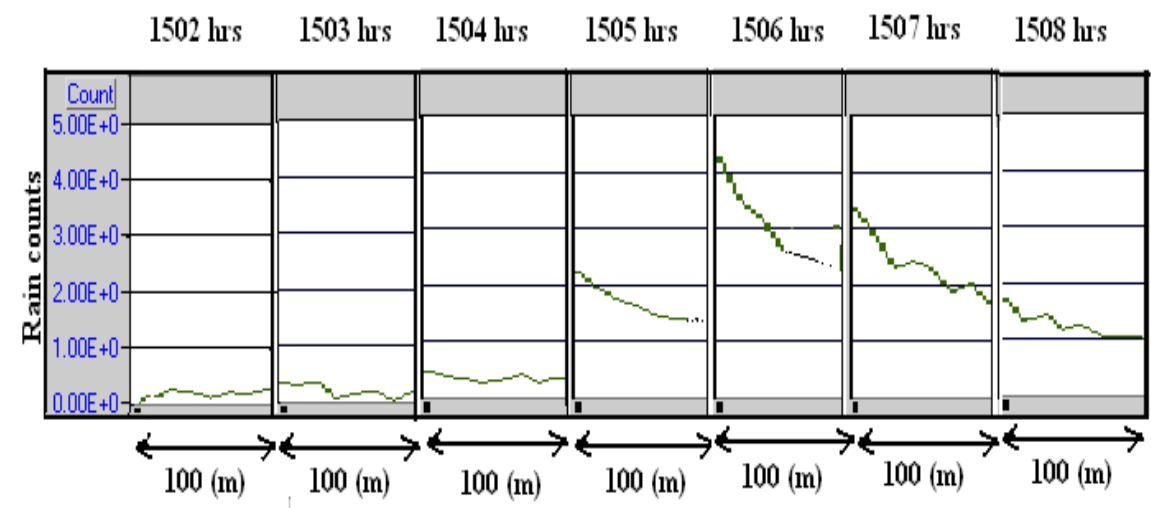

(a) 


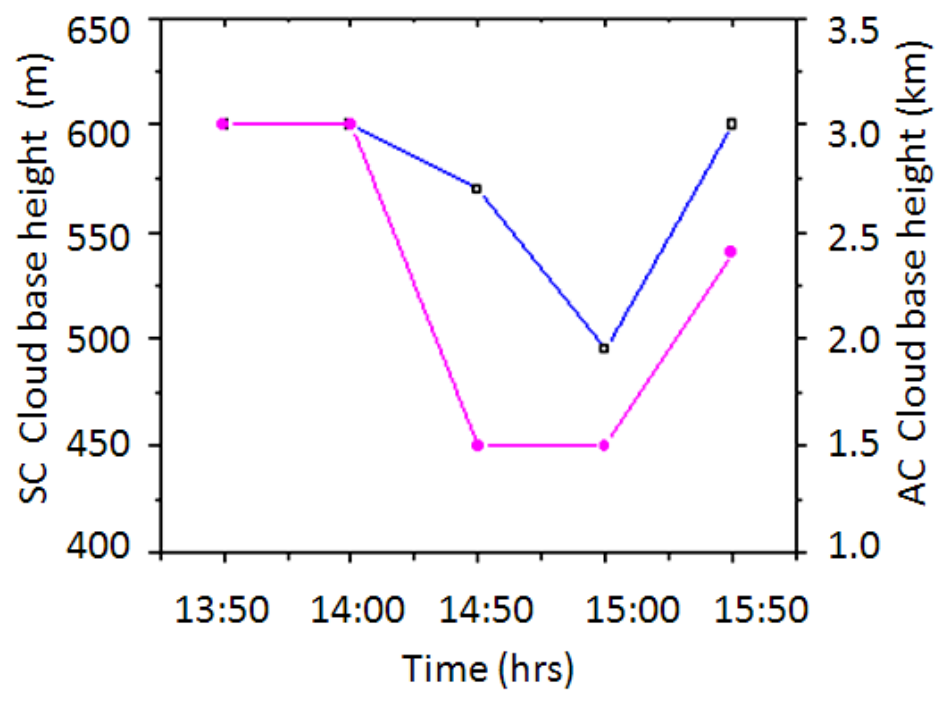

(b)

Figure 5. (a) Typical lidar counts during a rain event (18.9.2001).The arrow bar indicates each window has a length of 100m. (b) Shows cloud altitude variation seen by Radar (for both SC and AC cloud) prior to this rain event. The base moves up- wards after the short spell of rain. Rain data from rain gauge are not shown in the figure.

It is observed that while SC base height drops from $600 \mathrm{~m}$ to $450 \mathrm{~m}$, the AC descends down from 3.0 $\mathrm{km}$ to $2.4 \mathrm{~km}$ before this surface rain is recorded. This observation of lidar and radar agree on the point on pre-precipitation descent of cloud base, supporting our defined cloud features from lidar echogram. In the next article the calibration process converting lidar counts to rain rate is discussed. For this purpose disdrometer data on RSD has been used, the justification of the use of this instrument here has already been explained.

\subsubsection{Calibration lidar counts to rain rate $(\mathrm{mm} / \mathrm{h})$}

Rain rate (R) is evaluated from number density of drops from Raindrop Size Distribution (RSD) (Barbara et al., 1994) profiles of disdrometer. The rain-drop number density N (D) is then translated to the rain rate $\mathrm{R}$ by using relation (1) [Timothy et al., 1995], which is:

$$
R=6 \pi \times 10^{-4} \sum D_{i}^{3} N\left(D_{i}\right) V\left(D_{i}\right) \Delta D_{i} \mathrm{~mm} / \mathrm{hr}
$$

Here, $\mathrm{D}$ is the raindrop diameter $(\mathrm{i}=1,2,3 \ldots)$, in $\mathrm{mm}, \mathrm{N}(\mathrm{D})$ is the number density (in $\mathrm{mm}^{-1} \mathrm{~m}^{-3}$ ) of the drops and V (D) is the terminal velocity of the drop and rain rate $\mathrm{R}$ in $\mathrm{mm} / \mathrm{hr}$. To formulate a general 
relation between lidar counts and rain rate, a number of observations are made simultaneously with lidar and distrometer. A calibration curve is then drawn by associating these two parameters as shown in.

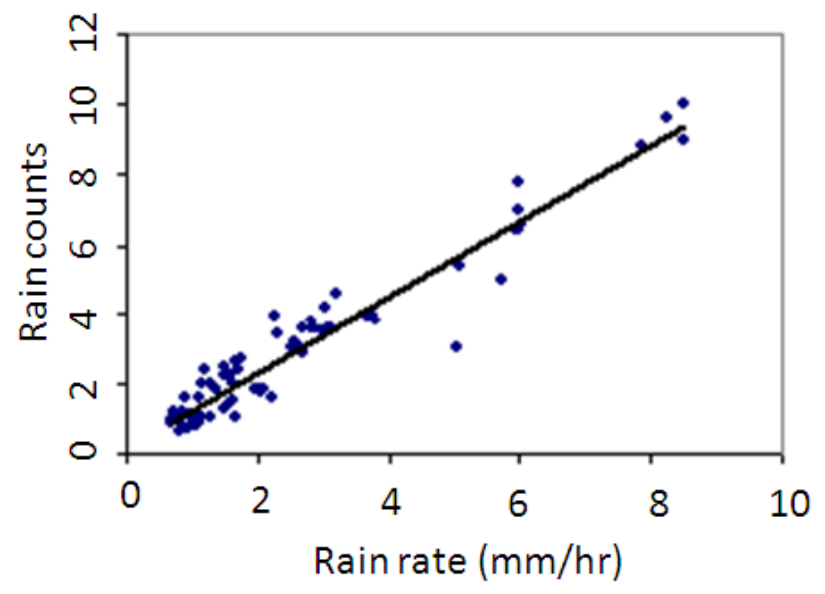

Figure 6. Calibration curve (best fit) associating rain counts from lidar and rain rate (mm/hr) calculated from RSD through disdrometer for very low rain rate situations. Each point is an average of 3 observations.

Once the conversion relation between lidar counts and $\mathrm{R}$ is established, we correlate this result with conventional rain gauge to make it suitable for practical applications. A comparative assessment of rain rate measured by lidar and rain gauge is presented in table I for low rain situations. It is found that average values received from lidar and rain gauge bear good correspondence, though in most sensitive mode when lidar count in one bin time of 20s is taken, rain rate from lidar is higher by $10 \%$ compared to rain gauge output.

Table I

Rain rate measured from lidar counts and that obtained from rain gauge

\begin{tabular}{|l|l|l|}
\hline Date and period & Rain rate from lidar & $\begin{array}{l}\text { Rain rate from rain } \\
\text { gauge }\end{array}$ \\
\hline $\begin{array}{l}\text { 19.10.2001,15:00-15:25 } \\
\text { hrs }\end{array}$ & $3.0 \mathrm{~mm} / \mathrm{hr}$ & $2.8 \mathrm{~mm} / \mathrm{hr}$ \\
\hline $\begin{array}{l}3.10 .2001, \quad 12: 30-12: 45 \\
\text { hrs }\end{array}$ & $1.0 \mathrm{~mm} / \mathrm{hr}$ & $0.9 \mathrm{~mm} / \mathrm{hr}$ \\
\hline $\begin{array}{l}5.10 .2001, \quad 10: 45-11: 00 \\
\text { hrs }\end{array}$ & $1.0 \mathrm{~mm} / \mathrm{hr}$ & $1 \mathrm{~mm} / \mathrm{hr}$ \\
\hline
\end{tabular}

\section{Discussion}

The study was confined only to pre and post monsoon periods as heavy downpours during monsoon smears out events in the lidar echogram. The exercise however demonstrates that lidar is a very effective tool for recording fine resolution movements of cloud base prior to a precipitation and also shows 
possibility of measuring low rain rate with fine temporal definitions not possible through conventional instruments. The latter is reflected even case of average rain rate. Accuracy of lidar observation for low rain situation may be $10 \%$ higher than obtained from conventional rain gauge.

The high aerosol population at the background as shown by the lidar prior to a rain event is significant but regarding role of aerosols in cloud seeding as reported by other workers [Graß1,1975 ; Kai et al., 1998 ; Kriger , 2002], we do not have direct observational facility of examining such activities but we take a close view of lidar return for obtaining possible coupling scenario between aerosol and cloud development process. With this aim we present in Figure 7 a set of cloud-aerosol relation. It shows a typical aerosol profile taken at 14:50:25 hrs where peak aerosol normalized counts received is 1.00 at $1 \mathrm{~km}$ height. After 20s i.e. at 14:50:45 hrs, a two-fold enhancement of counts is seen as shown in frame b of Figure 7. Then within 2 minutes (frame c of Figure 7), a clear cloud layer is formed at $500 \mathrm{~m}$ associated with decrease of aerosol counts. The counts further decrease (frame d) after formation of the well developed cloud. The observation gives an indirect approach for identifying seeding mechanism between aerosol and cloud; which can be further substantiated by analyzing aerosol optical properties in situation of Figure 7. So to assess modifications imposed on optical parameter of aerosols by the cloud development process, the extinction coefficient $(\sigma)$ of aerosol is determined for cloudless, cloudy and in near precipitation environment.

$14: 50: 25$

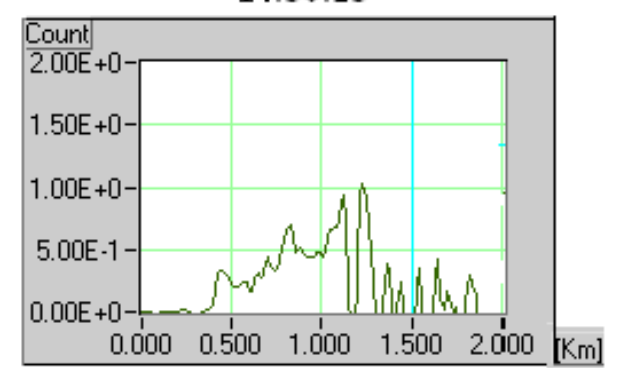

(a)

$14: 52: 26$

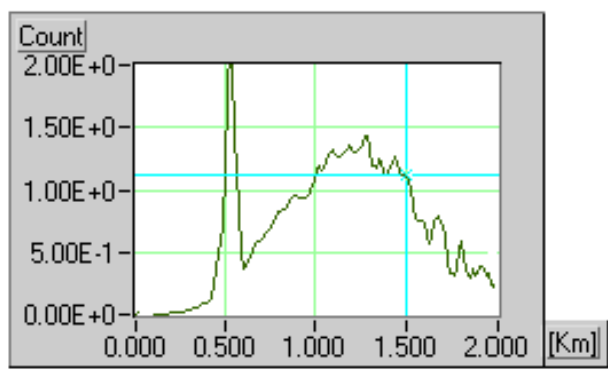

(c)
14:50:45

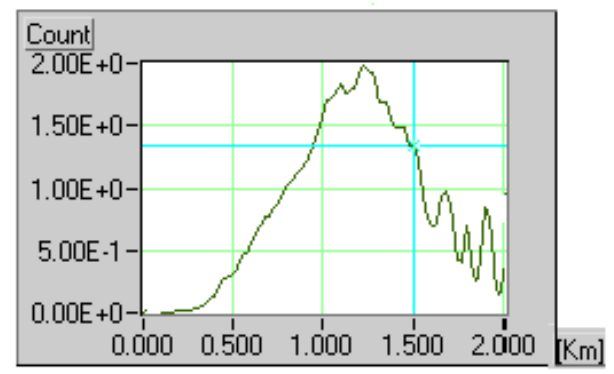

(b)

14:52:47

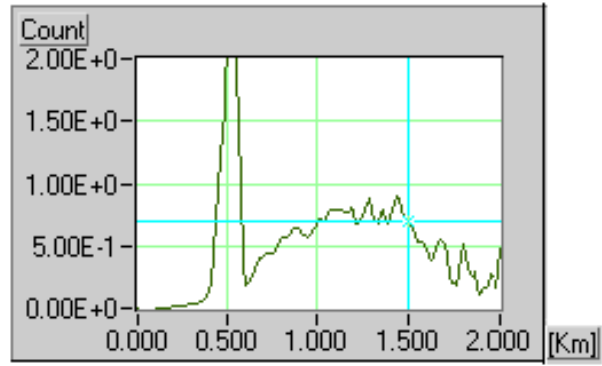

(d)

Figure 7. Displays cloud growth with aerosols. Aerosol profiles are presented (a) at 14:50:25 hr and (b) after $20 \mathrm{~s}$; Note enhancement of aerosol by two folds just after 20s from sounding time shown in (a). A low altitude cloud is developed after 1:41minute (c) and along with it one can note a decrease of aerosol counts. (d) Shows that with the increase of strength of this cloud layer, aerosol count decreases further. 
In figure 8(a) a typical temporal variation of aerosol- $\sigma$ in presence of medium height cloud and in absences of such cloud is shown . It is seen that $\sigma$ remains almost invariant irrespective of presence of such clouds. But modification of $\sigma$ in presence of low lying rain bearing cloud is apparent as can be seen from Figure 8(b). In this situation the $\sigma$ value was increased by 7 fold just before the precipitation event of 15:06 hrs, compared to a cloud free situation and one can also see that presence of low lying cloud (here at 15:03-15:05 hrs) may significantly influence $\sigma$ of aerosol, unlike a high/medium cloud. This analysis suggests that identification of type of a cloud with special reference to a precipitating or non precipitating one is possible by examining $\sigma$ values of aerosols. One can also asses the status of the atmosphere from extinction coefficient profile during the conversion process of $\sigma$ from raw backscatter counts through "lidar ratio $\mathrm{S}(\sigma / \beta)$ " that depends on dry/ cloudy/rainy situation [Devi et al., 2009].

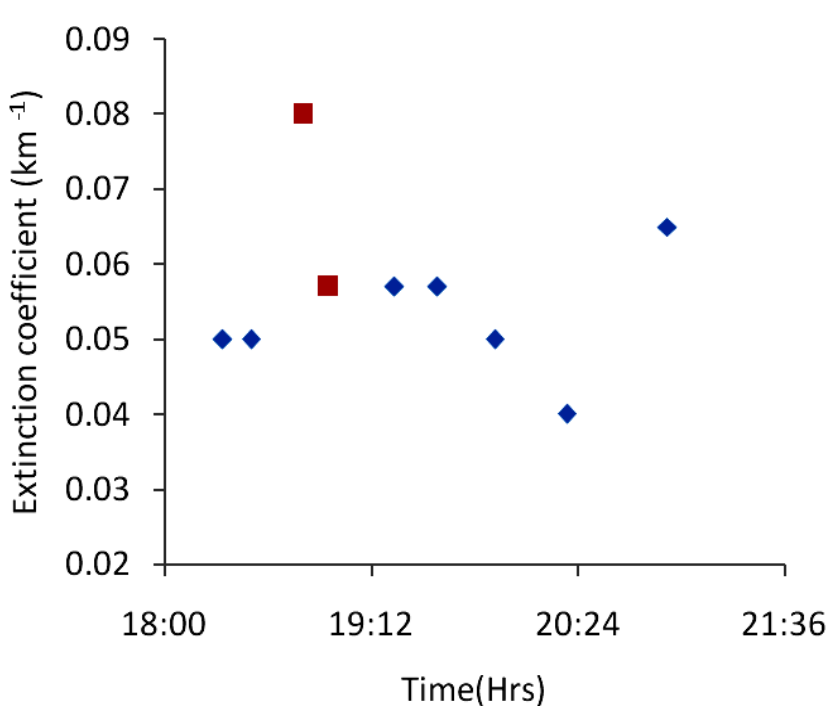

(a)

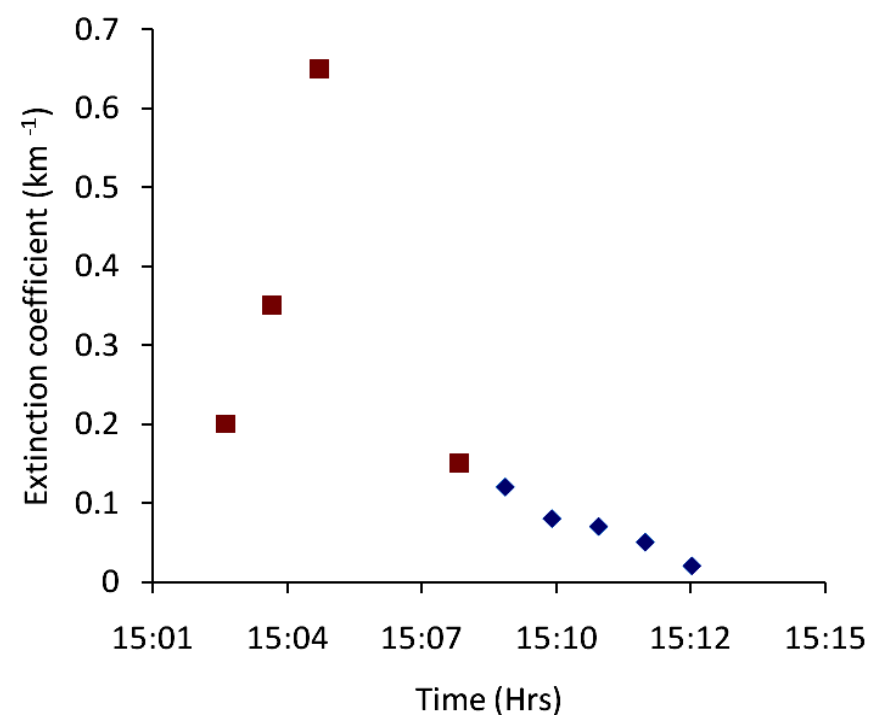

(b)

Figure 8. (a) Shows aerosol extinction coefficient (7.2.2001) when no cloud is seen in the echogram (diamond mark) and when high cloud at around $5 \mathrm{~km}$ is present (square mark). Note that there is practically no influence of cloud at $5 \mathrm{~km}$ on aerosol extinction coefficient. In (b) aerosol extinction coefficient is seen to be increased in presence of low lying cloud (marked by square) (18.9.2001) and the $\sigma$ value reaches maximum just before surface rain occurs. During rain-period (from 15:06 hrs to 1508 hrs extinction coefficient cannot be measured.

This analysis thus presents versatility of aerosol lidar in determining optical parameters of aerosols with fine details and also demonstrates that influence of cloud on aerosol optical parameter can be obtained through its highly resolved optical parameters. 


\section{Conclusion}

Micro-pulse lidar can effectively be used for identifying both microscopic and macroscopic features of aerosols and their association with cloud. The paper demonstrated its capability in identifying precipitation condition and also in rain rate evaluation. Fast changing dynamical parameters of the atmosphere available from lidar through optical parameters of aerosols and clouds ,will be adopted in future as inputs while framing aerosol-cloud interactive models.

\section{Acknowledgement:}

The authors acknowledge with thanks the financial support received from the Ministry of Information and Technologies, India for carrying out the project. The authors also thankfully acknowledge the scientific and engineering support offered by Prof. N. Takeuchi of Chiba University, Japan towards the project. The authors also thank the ATEC , Assam for offering financial support for continuing the data analyses work

\section{References}

Baishya, R., Devi, M. and Barbara, A. K, Software for lidar data analysis: development and application on MPL setup. Ind Jr. Radio and Space Phys., 32, 114-117.2003.

Barbara, A. K., Devi, M., Sharma, S. and Timothy, K.I. Microwave Propagation Characteristics: A study over Assam Valley with respect to tropospheric parameters. Final report of the project sponsored by Department Of Electronics, Government of India.1994.

Bian, H., Chin, M., Rodriguez, J., Yu, H., Penner, J. E., and Strahan, S., Sensitivity of aerosol optical thickness and aerosol direct radiative effect to relative humidity. Atmos. Chem. Phys. 9, 2375-2386, 2009.

Campbell, J.R., Dennis, L.H., Spinhirne, J.D., Scott,III, V.S., Turner, D.D. Operational processing and cloud boundary detection from Micro Pulse Lidar data, in: Singh, U.N., Ismail S. and Schwemmer, G.K. (Eds.), Proceedings of $19^{\text {th }}$ ILRC, pp. 119-210, 1998.

Clothiaux, E.E., Mace, G.G., Ackerman, T.P., Kane, T.J., Spinhirne, J.D, Scott, V.S. An automated algorithm for detection of hydrometeor returns in micro pulse lidar data. J Atmos and Ocean Techn, 15, 1035-1042,1998.

Devi M. and Barbara, A.K., Development of a Portable lidar, Final report of project on Development of a Micro pulse Lidar, sponsored by Ministry of Information Technology, Government of India. 2004.

Devi, M., Barbara, A. K., Saikia, M. and Chen, W. Vertical distribution of optical parameter of aerosol by using portable atmospheric lidar system of Gauhati University. Ind. Jr. Radio \& Space Phys., 37(5), 333-340. 2008.

Devi Minakshi , Barbara Ananda Kumar, Saikia Manoj, Choudhury Bandita , Sarmah Hemanta. Micro pulse Lidar: a tool for analyzing interactive relation between aerosol and cloud formation. International Journal of Engineering Sciences and Management . II, 82-94. 2012.

Graß1, H., Albedo reduction and radiative heating of clouds by absorbing aerosol particles, Contributions Atmospheric Physics, 48, 199-210. 1975. 
Hobbs, P.V., in Aerosol cloud climate interactions, Academic Press, Inc., New York. 1993.

Kai, K., Wakiyama, K., Fujii, M., Niwano, K., Muramatsu, D., Abo, M., Nagasawa, C., Murayama, T., Okada, K., Hara H. and Nakajima, H. Lidar network and airborne observation of the cloud street over Tokyo in summer, in: $19^{\text {th }}$ Proceedings of ILRC, Singh, U.N., Ismail S. and Schwemmer, G.K. (Eds.), pp. 107-110. 1998.

Kato, S., Clothiaux, E.E., Mace, G.G. and Liljegreen, J.C. Doppler radar and microwave radiometer derived Stratus cloud particle size distribution, Tenth ARN7 Science Team Meeting Proceeding, San Antonio, Texas. 2000.

Kriger, O .The indirect aerosol effect over Europe. Geophysical Research Letter, 29, 31-1-31-4. ., 2002.

Olsen, R.L., Rogers D.V. and Hodge, D.B. The $\mathrm{R}^{\mathrm{b}}$ relation in calculation of rain attenuation, IEEE Trans, AP-26, 318-329.1978.

Spinhirne, J.D., Micro Pulse Lidar, IEE Transaction on Geoscience and Remote Sensing, 13, 48. 1993.

Spinhirne, J.D., Campbel, J.R., Dennis, L. Autonomous fulltime cloud profiling at arm sites with Micro Pulse Lidar Symposium on Lidar atmosphere http://www.ams.confex.com/ams/annual2000/lidar/index.htm), 2000.

Stokes, G.M. and Schwartz, S.E. The Atmospheric Radiation Measurement (ARM) Program: Program background and design of cloud and radiation test bed. Bull. Amer. Meteorol. Society, 75, 1201-1221. 1994.

Timothy, K.I., Sharma, S., Devi M. and Barbara, A.K. Model for estimating rain at frequencies in range 6-30 GHz, Electronics Letters, 31, 1505-1506. 1995. 